\title{
Fire in the Records: The Dark Side of Knowledge Management
}

\author{
Mark Hoksbergen \\ University of Auckland \\ m.hoksbergen@auckland.ac.nz \\ Johnny Chan \\ University of Auckland \\ jh.chan@auckland.ac.nz
}

\author{
Gabrielle Peko \\ University of Auckland \\ g.peko@auckland.ac.nz
}

\author{
David Sundaram \\ University of Auckland \\ d.sundaram@auckland.ac.nz
}

\begin{abstract}
This paper discusses the implications of buyers and sellers being influenced by the information they receive and how that impacts their decision-making process in the context of a high-value low-frequency transaction (HVLFT). Using an exploratory case study, we explore a dark dimension of knowledge where tacit or explicit knowledge has been lost, distorted, suppressed, misrepresented, or misappropriated resulting in ambiguity and increased risk in decision making. The case study focuses on the decision-making process and the information flow seen from the perspective of different stakeholders involved in a HVLFT. Based on this case study we propose, articulate, and apply a model that explicitly acknowledges the dark side of knowledge. Our findings suggest the need for the application of convergent technologies to ameliorate the risk and asymmetricity caused by the dark side of knowledge and enhance governance particularly in the context of HVLFT.
\end{abstract}

\section{Introduction}

In a commercial setting, the dark side of knowledge has been widespread and has existed ever since we have been trading goods. There has always been tension between profit and honesty. This tension often leads to the misuse of asymmetric information between a seller and a buyer [1]. In a high-value low-frequency transaction (HVLFT), we are committing a large part of our financial wealth to an asset that we may only buy or sell a few times in our lifetime. The low-frequency means that a buyer is per definition a novice buyer and cannot leverage his decision making on past experiences. [4]. The HVLFT can have a lifelong financial impact on a buyer that is unaware of the risk associated with the purchase. Also, the decision-making process of a buyer is affected by a HVLFT. This decision- making process could be compared to asking a person to walk across a board laid down on a livingroom floor (i.e. regular transaction) and then asking them to repeat that same feat but suspending that same plank across a canyon with a 100-meter drop on both sides (i.e. HVLFT).

To support the decision-making process of a novice buyer we propose the TEX model $[25,26]$, adding a dimension to the classic tacit and explicit divide of information [11]. The TEX Model has been used as a guide in our case study, whilst interviewing 31 participants in the New Zealand (NZ) real estate industry.

\section{Knowledge Management}

Knowledge management is often viewed as the interaction among people, process, and technology. This interaction is frequently portrayed in a firm setting. Brooking [5] advances a broader view and defines knowledge management as the approach we manage human-centred assets. Its function is to guard and grow knowledge owned by individuals, and where possible, transfer the assets into a form where they can be more readily shared by others. The crux of the theory is to devise different strategies to capture the tacit knowledge from individuals and convert them into explicit knowledge, making them readily available and transferable to many [32].

\subsection{Tacit and Explicit Knowledge}

The distinction between tacit and explicit knowledge is a fundamental concept in knowledge management [11]. It was first purported by Polanyi [42], "we know more than we can tell." The difference between tacit and explicit is also acknowledged by Alavi and Leidner [2]. Nonaka and Takeuchi [41] define tacit knowledge as "personal knowledge embedded in individual experience and involves intangible factors such as personal beliefs, perspective and value systems." Explicit knowledge is the converse of tacit knowledge. Explicit knowledge can be expressed in code and is not subject to multiple interpretations, while tacit knowledge can be subdivided into knowledge that has not been formalised and knowledge that cannot be formalised. Hedesstrom and Whitley [23] emphasise 
that once knowledge has been formalised, it becomes explicit. This is further extrapolated by Nonaka and Takeuchi [41] in their SECI model showing the complexity of coding tacit knowledge into explicit knowledge. Dalkir [11] furthermore posits that the primary division in knowledge is between tacit and explicit knowledge. However, Collins [10] notes that tacit knowledge is a relative concept: what is easily articulated by one person may be very difficult to externalise by another. Thus, the same content may be explicit for one person and tacit for another. Underlying the terminologies of tacit and explicit knowledge there is a plethora of literature referring to implicit knowledge, which is simply defined as all non- explicit knowledge and is interwoven with the term tacit knowledge [13].

Davenport and Prusak [12] describe knowledge as a mix of experiences, contextual information, values, and expert insights. Within organisations, this becomes embedded not only in document repositories but also in routines, processes, and practices. In contrast, Fahey and Prusak [19] argue the importance of creating a shared context. The starting point of "managing knowledge" is to convey the shared context between the individuals participating in knowledge sharing. However, a lack of trust impacts the willingness to share information between stakeholders while, conversely, the sharing of tacit knowledge can be induced by trust [7].

We can synthesise the abovementioned literature in a simple dynamic model (Figure 1). Where a body of knowledge is divided into tacit and explicit knowledge. There is a flow of knowledge being codified from tacit to explicit, and there is explicit knowledge that is lost and reverted to tacit knowledge.

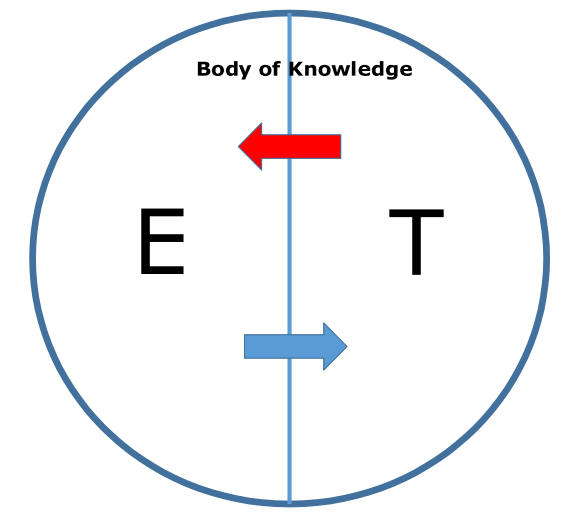

Figure 1. Classic tacit / explicit division

To give two practical examples from the NZ real estate industry, the Red arrow in Figure 1 indicates the flow of tacit to explicit knowledge: the real estate agent voices that the house situated on a cliff face has been there for 40 years and has never moved. A geo-tech engineer makes this explicit by testing the land and providing a detailed report on potential problems. Conversely, the Blue arrow indicates the flow of explicit to tacit knowledge; when a house is sold but the warranties are not transferred to the new owner. The explicit information is lost and becomes tacit.

\subsection{Knowledge asymmetry in HVLFT}

Knowledge sharing in a competitive environment has its own set of challenges. Stakeholders participating in a HVLFT often face the issue of information and knowledge asymmetry. Asymmetric information and knowledge are broad domains and have been of concern from the very origins of humanity. There have been many approaches to obtain a fairer outcome of transactions. One of the earliest on record is the envyfree cake cutting techniques based on "divide and choose" as described in the Bible (Book of Genesis, Chapter 13). Economists have discussed the asymmetric information problem since the eighteenth century [22, 35]. An asymmetric information taxonomy was formalised in the $70 \mathrm{~s}$ through several prominent contributions. Akerlof [1] describes the negative financial impact that information discloser has on a transaction from a seller's perspective. The taxonomy is further extrapolated by three models underpinning the behavioural experience between the sender and receiver of asymmetric information. First, we have the Adverse Selection Model proposed by Rothschild and Stiglitz [47]. It is still used in economics, insurance, and risk management today, portraying the seller having more information than the buyer. Second, the Moral Hazard Model explains the change in the behaviour of a buyer or a seller due to the lack of perceived risk [27]. Finally, Spence [50] describes two parties that have access to different information signified by the Signalling Model - observing the knowledge gap between an organisation and a job applicant.

In the quest to finding the best negotiation tactic/strategy in an environment dominated by asymmetric information, a fundamental principle of game theory was developed, and aptly named the revelation principle [18]. This principle was founded on the agent being incentivised, to tell the truth [30, 39]. This principle provides the discovery of the best negotiation mechanism in the least amount of time. Opposing the revelation theory is the Bayesian game theory. This theory relies on negotiating agents having incomplete information [37, 39]. Under the Bayesian game theory and the auction strategy, selling an object and trying to maximise the return from multiple buyers is valid from a seller's perspective [38]. Various types of auctions can be used, e.g., English, Dutch, and Sealed 
bid [45]. The Bayesian game theory is currently the modus operandi for most HVLFT [1].

\subsection{The dark side of knowledge}

The dark side of knowledge is conceptualised as an unwillingness to share information so as not to lose a competitive advantage [48]. The dark side of knowledge management and the unethical motives that endanger capturing knowledge include distortion (e.g. manipulating specific knowledge in favour of particular interests, viewpoints, or beliefs); suppression (e.g. creating obstacles and using the knowledge that is contrary to particular interests); and misappropriation (e.g. modification, theft, or inappropriate revelation of knowledge) [3]. In a transaction with multiple unaligned stakeholders, the dark side needs to be understood on how it could influence the information shared among them. If we focus on the dark side of knowledge in the context of a HVLFT, then we need to understand the interplay between the different stakeholders within a transaction.

In addition, sticky knowledge and leaky knowledge are two other important concepts that characterise knowledge sharing. There are two schools of thought on the stickiness of knowledge. One is the educational view that knowledge stickiness measures the knowledge that retains with the student. And the other is the management view of sticky knowledge that occurs when tacit knowledge is difficult to codify and transfer [20]. For knowledge surrounding HVLFT, we will adhere to the management view of sticky knowledge. Motivational barriers to knowledge transfer are well known in the management literature [28]. Resistance to change, competitive advantage, job protection, and lack of incentives are potential barriers; and transfer of knowledge is often laborious, time- consuming, and challenging [51]. Within an organisation, stickiness is exacerbated by the difficulties in that process of transferring knowledge [51]. Knowledge leakage occurs when information seeps out of the system, causing knowledge to be lost. For a HVLFT, it is important to distinguish the difference between the dark side of knowledge and knowledge leakage. The main difference is that the leakage of information is an unintentional loss of knowledge, and the dark side is the intentional misuse of knowledge. To use a metaphor, we see information flowing through plumbing pipes between stakeholders. The stickiness causes blockages in the flow, often through time and changing stakeholders; and the leakage is the loss of information [15]. The literature makes a distinction of other concepts of knowledge apart from the classic tacit and explicit divide, as described above. Also, the understanding, experience, and learning are important considerations in a HVLFT. The different forms of such knowledge (data, information, knowledge, wisdom, understanding, experience, and/or learning) which is neither tacit nor explicit, we deem as belonging to knowledge dimension $\mathrm{X}$. More formally we define knowledge in dimension X as tacit or explicit knowledge that has now been lost, distorted, suppressed, misrepresented, or misappropriated resulting in ambiguity and increased risk in decision making.

\section{The Case Study}

\subsection{Background}

The primary research instrument was an exploratory case study using semi-structured interviews. According to Yin [52], identifying the unit of analysis and the "key" participants are vital to a case study design. The unit of analysis was the NZ real estate industry. During the pilot study, six main categories of stakeholders were identified: buyer, seller, real estate agent, government, lawyer, and specialist. The NZ residential real estate has all the characteristics of a HVLFT. The stakeholders mentioned above have all the characteristics needed to understand the three research questions: 1) what asymmetric information in a HVLFT is, 2) what causes asymmetric information in a HVLFT, and 3) how we counterbalance asymmetric information in a HVLFT. The steps undertaken in the interview process are presented in Figure 2 and discussed in the following section.

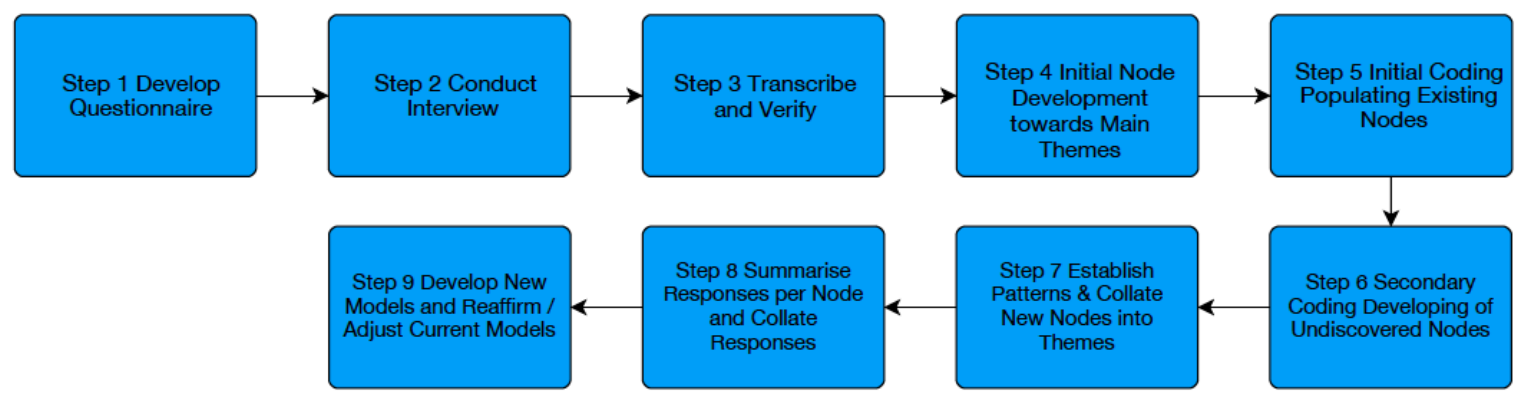

Figure 2: Steps in the interview process 


\subsection{Process}

This qualitative case study allows exploratory research into an industry and to build a theory on the current situation from within, utilising deductive and inductive process to formalise the theory [16].

Step 1: A questionnaire was designed to understand the viewpoint of the stakeholders involved in a residential real estate transaction in NZ. The base questionnaire focussed on the decision-making process within a transaction between a buyer and a seller. For the other stakeholders, a personalised version of the questionnaire was developed, which focus on their specific role within the transaction.

Step 2: Semi-structured interviews were conducted at a place of the participants choosing. Due to the COVID 19 lockdown, most of the interviews were conducted using Zoom the video conferencing application.

Step 3: Each interview was transcribed and returned to the participant in order to check for inaccuracies or privacy breaches. If amendments were made they were returned to the participants to recheck. This reiterative process was completed once the participants agreed that the data could be used for the intended research purpose.

Step 4: Initial nodes were developed for responses from the participants that aligned with three main themes (a) the three research questions (b) the phases of the Decision Making Process Model [25] and (c) the TEX Model.

Step 5: The nodes were populated by the responses (answers and statements) given by the various participants. The text was highlighted and collated with the nodes using practical examples and responses of agreeing or disagreeing with the above- mentioned themes.

Step 6: The text was analysed a second time extracting nodes that were outside the scope of the three described themes. Highlighting differences in geographical location, perceived risk, emotional responses, decision making, and processes that needed to be improved. Also, the text highlighted in step 5 was used for multiple nodes where applicable.

Step 7: Patterns were established, new nodes were aggregate and new themes developed.

Step 8: The responses per node were summarised and the responses per participant collated as "favourable/against/ neutral". A framework of stakeholders and their responses per theme was created.

Step 9: New models were developed, and current models reaffirmed or refined.

\subsection{Sample Size}

There is a low level of transparency regarding sample sizes in an industry-wide case study [6, 33]. Often, authors suggest that saturation needs to be achieved, inferring that the addition of more stakeholders did not add anything to the analysis. Mason et al. [33] research on 429 doctoral theses found the mode was 25 participants. Malterud et al. [31] propose the concept of "information power" to ascertain the sample size needed for a qualitative study. The higher the information power is the smaller the sample size can be. Information power is determined by five criteria; represented in Table 1.

Combining the findings from Mason et al. [33] and Malterud et al. [31], our sample size was 31 participants. Initially, the number of participants was variable depending on the representation of the various voices within a group of stakeholders and dictated by the saturation point of new insights gained [36].

\begin{tabular}{|l|l|c|}
\hline $\begin{array}{l}\text { Criteria Info } \\
\text { Power }\end{array}$ & HVLFT in NZ Real Estate & $\begin{array}{c}\text { Sample } \\
\text { Size }\end{array}$ \\
\hline $\begin{array}{l}\text { Aim of the } \\
\text { study }\end{array}$ & Narrow (HVLFT) \\
\hline $\begin{array}{l}\text { Sample } \\
\text { specificity }\end{array}$ & Dense (Expertise) & \\
\hline Use of theory & Applied / Theoretical & \\
\hline $\begin{array}{l}\text { Quality of } \\
\text { dialog }\end{array}$ & Strong (Experience) & \\
\hline $\begin{array}{l}\text { Analysis } \\
\text { strategy }\end{array}$ & Cross Case (Different Fields) & \\
\hline
\end{tabular}

Table 1: Change in information power

\subsection{Stakeholders}

Identifying and selecting the stakeholders followed a structured approach to secure a representative sample.

1. For the buyers, a mix of novice (first-time) and experienced (more than 5 properties purchased) buyers were selected. Also, a combination of rural and urban backgrounds were included to provide an in-depth picture.

2. For the seller, a mix of novice (first-time) and experienced (more than 5 properties sold) sellers were selected. Also, a combination of rural and urban backgrounds were included to provide an indepth picture.

3. The real estate agent had a minimum of 10 years' experience. Such experience provided insights into changes that occurred in the industry over time. And, a plethora of practical examples of the possible misuse of asymmetric information between buyer and seller.

4. Government participants with knowledge of council requirements, which are linked to the resource management act (RMA), were selected. 
This information is crucial in purchasing a property in NZ.

5. A lawyer who operated in the rural context and one that operated in an urban context were selected. Both specialised in conveyancing and had more than 10 years' experience.

6. A mortgage specialist who could provide insights into the financial impact of purchasing a property was selected.

7. Specialists were selected who are commonly requested to produce reports and services that are linked to a property sale.

To generalise these stakeholders beyond the NZ real estate market we aligned the main stakeholder categories with the Governance, Risk and Compliance (GRC) model [44]. We further divided the seven main stakeholders into smaller sub- categories, which also aligned with the GRC model, as shown in Table 2.

\begin{tabular}{|c|c|c|c|c|}
\hline \begin{tabular}{l|}
$\mathbf{G}$ \\
$\mathbf{R}$ \\
$\mathbf{C}$
\end{tabular} & $\begin{array}{c}\text { Main } \\
\text { Category }\end{array}$ & $\#$ & Sub-Category & $\#$ \\
\hline \multirow{2}{*}{ 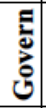 } & \multirow[b]{2}{*}{ Council } & \multirow[b]{2}{*}{2} & Council RMA Manager & 1 \\
\hline & & & $\begin{array}{c}\text { Council Compliance } \\
\text { Officer }\end{array}$ & 1 \\
\hline \multirow{8}{*}{$\frac{.0}{2}$} & \multirow{2}{*}{ Buyer } & \multirow{2}{*}{7} & $\begin{array}{c}\text { Experienced Buyer }>5 \\
\text { properties }\end{array}$ & 2 \\
\hline & & & $\begin{array}{l}\text { Novice Buyer (Rural / } \\
\text { Urban) }\end{array}$ & 5 \\
\hline & \multirow{2}{*}{ Seller } & \multirow{2}{*}{6} & $\begin{array}{c}\text { Experienced Seller }>5 \\
\text { properties }\end{array}$ & 2 \\
\hline & & & $\begin{array}{c}\text { Novice Seller (Rural / } \\
\text { Urban) }\end{array}$ & 4 \\
\hline & \multirow{2}{*}{ Agent } & \multirow{2}{*}{4} & $\begin{array}{c}\text { Urban Agent }>10 \text { year's } \\
\text { experience }\end{array}$ & 2 \\
\hline & & & $\begin{array}{c}\text { Rural Agent }>10 \text { year's } \\
\text { experience }\end{array}$ & 2 \\
\hline & \multirow{2}{*}{ Banker } & \multirow{2}{*}{2} & Mortgage Specialist & 1 \\
\hline & & & Bank Employee & 1 \\
\hline \multirow{8}{*}{ 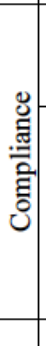 } & Lawyer & 2 & $\begin{array}{l}\text { Lawyer }>10 \text { year's } \\
\text { experience in } \\
\text { conveyancing }\end{array}$ & 2 \\
\hline & \multirow{6}{*}{ Specialist } & \multirow{6}{*}{8} & Builders Report & 2 \\
\hline & & & Valuer & 1 \\
\hline & & & Rental Agent & 1 \\
\hline & & & Builder & 2 \\
\hline & & & Building Compliance & 1 \\
\hline & & & Heritage & 1 \\
\hline & Total & 31 & & 31 \\
\hline
\end{tabular}

Table 2: Stakeholders interviewed

\subsection{Data Collection}

Participants were asked open-ended questions and encouraged to describe situations in significant detail. They were allowed to ask questions to clarify the posed questions. The estimated time per interview was between 20 and 30 minutes, however, the duration was extended when new insights were being uncovered. The semi-structured interviews were recorded and transcribed. Codes were used to assign meaning to the descriptive information compiled during the study [34]. The qualitative data analysis software (NVivo) was utilised to explore asymmetric information in HVLFT, the causation of asymmetric information in HVLFT, and how asymmetric information in HVLFT can be counterbalanced. The coding process was supported by procedural memos to keep track of any changes in the thematic nodes [9].

The NZ residential real estate industry was used to scope the case study and view the phenomena of asymmetric information in a HVLFT through the eyes of participants. Realising the pitfalls of the dramaturgical model [21], the follow-up questions asked during the interview process produced the most explanatory data. Eliciting the stakeholders to provide their un-reserved opinions, consequently captured unanticipated information [17]. Listening to the subliminal meaning behind statements and reflecting back to deepen the conversation ensured that the meaning was understood [8]. The developed questionnaire was a guide to the interview allowing the researcher to switch between questions and ask supplementary questions to gain a deeper understanding on the participant's specific expertise.

\subsection{Interview Process}

The structure focused on the decision-making process and what information was needed to support this process.

- Decision-making process of a buyer/seller on the abstract level (macro)

- Decision-making process of a buyer/seller on a detailed level (micro)

- Negotiation process

- Information gathering process

- Trusting the information received from the different stakeholders

- Procedure how information is provided

- Technologies used to gather information and support a decision

- Data that is relied upon to make a decision

The questionnaire was specifically designed for the three main categories; buyer, seller, and real estate agent. For the other categories, tailor-made additional questions were drafted per participant to understand their specific role in the process.

The questions were designed to understand the phenomena of asymmetric information in a HVLFT from the perspective of the various stakeholders involved. Focussing on the social construct of how the stakeholders view a HVLFT [36].

As mentioned, the data was collected through semistructured interviews. The developed questionnaire was 
a guide to the interview allowing the researcher to switch between questions and ask supplementary questions to gain a deeper understanding of the participant's responses and expertise. Two categories of questions were asked about (a) the current process and their perceptions on the quality of information and (b) potential future scenarios that address some of the current problems by leveraging appropriate technology.

Current description of processes and perceptions of information quality:

- How they gather relevant information to support their decision.

- How they choose their information sources

- How they determine the market price

- How accurate they perceive the information to be

- How they trust the information received

- How they choose a property

- How they negotiate

- Potential procedural and technological responses that overcome current problems:

- How they would challenge potential mistakes made in the process

- How they would improve the process

- How technology can support their decision

- How they would like to receive the information needed

The participants were initially selected through personal networks and further recruitment through a snowballing process during the interviews. The participant received an invitation email with the participant information sheet (PIS) and a consent form (CF). Due to the COVID 19 Level 4 lockdown, all interviews were conducted through video conferencing (Zoom). The interviews were recorded via video (mp4) and audio (mp3). We recognise that video recording led to a more structured response from the participant, eliminating the noise that a face to face interview has. This, in-turn shortened the interview process by approximately 15 minutes (20 to 40 minutes). The interview was then transcribed. All the participant personal information was deleted, and their name replaced by a code. A copy was sent via email to the participants with a personal email thanking them and requesting them to check the transcript and comment on anything they do not want to be disclosed. We noticed in the initial interviews that the participants were very aware of their reputation, and any "negative" remarks made about other stakeholders in the industry were asked to be deleted.

The transcripts were imported into NVIVO software and auto coded per speaker. This provides the possibility to focus on the responses from each participant. Each transcript was coded line for line finding statements made on the common themes mentioned above. Also leaving room to code new and unexpected information presented in the interview. The participants also received a case classification on age (20-39, 40-59, 60+), gender (male, female), and geographical (urban, rural).

\subsection{Data Analysis}

The common themes between all stakeholders in a NZ real estate transaction are:

- Misappropriation of information

- Lack of available explicit information on a specific property

- Not understanding all the risks involved in purchasing a property

- Flaws in the current process of purchasing a property

- The financial implications in securing a property

- The rules and regulations faced by all experts

- Differences in the geographic area (urban, rural, international)

- It allows the following nodes to be aggregated:

- Explicit Information (available) (Council Property File, Legal (documentation), LIM Report, LINZ (title info), Specialist Reports)

- Geographical (differences) (International, Rural, Urban)

- Procedural Change (criticised or recommended) (Council, Legal, Real Estate, Specialist)

- X (examples) (Fraud, Misinformation, Not understood, Withheld Information)

\section{Research Artefacts}

\subsection{TEX Model}

Given the information gathered from the interviews, and from personal experience, there is a dimension missing in dividing a body of knowledge into tacit and explicit. We call this new dimension

$\mathrm{X}$. It aligns with the literature showing some forms of knowledge that are not fully captured by the classic tacit and explicit divide. Even if all information associated with HVLFT is presented explicitly, understanding them for a novice buyer can still be challenging [14]. Due to the low- frequency purchasing of high-value assets, the possibility of single, double, or triple loop learning is less applicable [4] among HVLFT. The terminology used by participants to describe tacit, explicit, and $\mathrm{X}$ are gathered in Table 3. X and its interactions with tacit and explicit are combined with the characteristics and relevant authors are shown in Table 4.

\subsection{Application of TEX}


The flows are depicted in the Dynamic TEX Model shown below in Figure 3 and illustrates the transformations of the different types of knowledge at the nexus/vortex between the tacit, explicit, and

$\mathrm{X}$. The TEX model is proposed through a HVLFT lens, and especially through the eyes of the stakeholders in the real estate industry. The TEX model can be applied to real estate transactions in NZ through the seven stakeholders: seller, buyer, council, lawyer, agent, banker, and specialist $[25,26]$. Table 5 presents just a few insights gained from the semi-structured interviews held and provides a starting point to segment the various stakeholders.

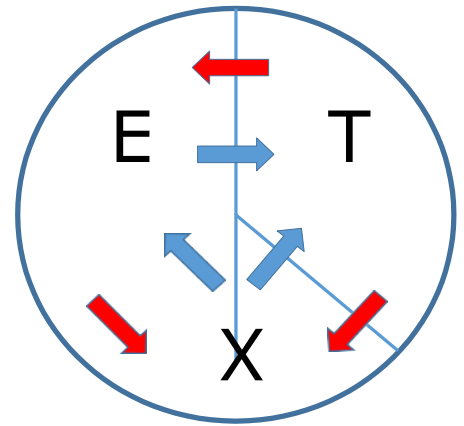

Figure 3. Dynamic TEX model

As mentioned before, the chance for having single, double or triple loop learning for the buyer in HVLFT is low because the opportunity to reflect on a mistake is rare. Since the seller often has the advantage of asymmetric information [40], that could lead to suboptimal decision making by the buyer. Besides from real $[43,46]$, asymmetric information and knowledge in a transaction have been studied in other contexts [1, $24]$ and business process design [49].

\begin{tabular}{|l|l|l|}
\hline Explicit & Tacit & $\mathbf{X}$ \\
\hline Easy to codify & Hard to codify & $\begin{array}{l}\text { Lack of } \\
\text { understanding }\end{array}$ \\
\hline Easy to share & $\begin{array}{l}\text { Difficult to } \\
\text { share }\end{array}$ & $\begin{array}{l}\text { Unwillingness to } \\
\text { share }\end{array}$ \\
\hline $\begin{array}{l}\text { Easily } \\
\text { transferred }\end{array}$ & $\begin{array}{l}\text { Hard to } \\
\text { transfer }\end{array}$ & Misappropriation \\
\hline $\begin{array}{l}\text { Easily } \\
\text { documented }\end{array}$ & $\begin{array}{l}\text { Hard to } \\
\text { document }\end{array}$ & Modification \\
\hline Externalised & Internalised & Hidden \\
\hline Structured & $\begin{array}{l}\text { Human } \\
\text { interpretation }\end{array}$ & Profit-driven \\
\hline Objective & Subjective & Slanted \\
\hline Rational & Cognitive & Loss of knowledge \\
\hline Understandable & Teachable & Misinformation \\
\hline $\begin{array}{l}\text { Context } \\
\text { independent }\end{array}$ & $\begin{array}{l}\text { Dynamically } \\
\text { created }\end{array}$ & $\begin{array}{l}\text { Creation of } \\
\text { obstacles }\end{array}$ \\
\hline $\begin{array}{l}\text { Challengeable } \\
\text { knowledge }\end{array}$ & $\begin{array}{l}\text { Hard to legally } \\
\text { challenge }\end{array}$ & Fraud \\
\hline
\end{tabular}

Table 3. Terminologies used for TEX

\begin{tabular}{|c|c|c|c|c|}
\hline \multicolumn{2}{|c|}{ Description } & Transformation & Characteristics & Authors / Considerations \\
\hline \multicolumn{2}{|c|}{ Sticky Knowledge } & $E=>X$ & $\begin{array}{l}\text { The knowledge that is hard or impossible to transfer into explicit } \\
\text { knowledge }\end{array}$ & Szulanski (2000) \\
\hline \multicolumn{2}{|c|}{ Leaky Knowledge } & $\mathrm{T}=>\mathrm{X}$ & Tacit knowledge is lost over time & \\
\hline \multicolumn{2}{|c|}{ Leaky Knowledge } & $E=>X$ & Explicit knowledge is lost (inadvertently) & Ferdinand \& Simm (2006) \\
\hline \multirow{3}{*}{ 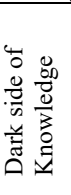 } & $*$ Distort & $\mathrm{T} / \mathrm{E}=>\mathrm{X}$ & $\begin{array}{l}\text { Manipulating specific knowledge in favour of particular interests, } \\
\text { viewpoints, or beliefs }\end{array}$ & Alter (2006) \\
\hline & *Suppress & $\mathrm{T} / \mathrm{E}=>\mathrm{X}$ & $\begin{array}{l}\text { Creating obstacles and using the knowledge that is } \\
\text { contrary to particular interests }\end{array}$ & Seidl (2007) \\
\hline & * Mis-appropriate & $\mathrm{T} / \mathrm{E}=>\mathrm{X}$ & $\begin{array}{l}\text { Modification, theft, or inappropriate revelation of } \\
\text { knowledge }\end{array}$ & Seidl (2007) \\
\hline \multicolumn{2}{|c|}{ Educational } & $\mathrm{T} / \mathrm{E}=>\mathrm{X}$ & $\begin{array}{l}\text { Not understanding explicit and/ or tacit information. Unable to } \\
\text { make an informed decision }\end{array}$ & Jones, et al. (1980) \\
\hline \multicolumn{2}{|c|}{ Learning } & $\mathrm{T} / \mathrm{E}=>\mathrm{X}$ & $\begin{array}{l}\text { Unable to adjust actions, assumptions, or context due to the low } \\
\text { frequency of specific transactions }\end{array}$ & Duguid (2005) \\
\hline \multicolumn{2}{|c|}{ Educational } & $\mathrm{X}=>\mathrm{T} / \mathrm{E}$ & Understanding on a specific body of knowledge increases & Dreyfus (2004) \\
\hline \multicolumn{2}{|c|}{ Learning } & $X=>T / E$ & Understanding the risk in a HVLFT & Argyris \& Schon (1974) \\
\hline \multicolumn{2}{|c|}{ Government Response } & $X=>E$ & $\begin{array}{l}\text { Regulations to improve the reliability of the information } \\
\text { provided. Through regulations or sanctions }\end{array}$ & $\begin{array}{l}\text { Increased fines for } \\
\text { misinformation, Anti-money } \\
\text { laundering bill }\end{array}$ \\
\hline \multicolumn{2}{|c|}{ Technological Response } & $\mathrm{X}=>\mathrm{T} / \mathrm{E}$ & Systems to support a HVLFT & $\begin{array}{l}\text { Blockchain, web } \\
\text { applications, IoT }\end{array}$ \\
\hline \multicolumn{2}{|c|}{ Procedural Response } & $X=>T / E$ & $\begin{array}{l}\text { Procedures in place to support government and } \\
\text { technological responses }\end{array}$ & $\begin{array}{l}\text { Owners information } \\
\text { registered, warranties linked }\end{array}$ \\
\hline
\end{tabular}

Table 4. Knowledge flow between TEX dimensions

The information inequality should be addressed by educating stakeholders about all three dimensions of the TEX model. The buyer needs to understand the tacit and explicit knowledge made available to them, and being aware of the motivation behind others to misuse X. For example, a novice real estate buyer presented with 
explicit knowledge such as technical drawing or report, may not understand the implication of them to the purchase of the property. This education layer is added to the TEX Model as seen in Figure 4.

\begin{tabular}{|c|c|c|c|}
\hline $\begin{array}{l}\text { Stake- } \\
\text { holder }\end{array}$ & Explicit & Tacit & $\mathbf{X}$ \\
\hline Seller & Chattel list & $\begin{array}{l}\text { Minimum } \\
\text { price } \\
\text { willing to } \\
\text { accept }\end{array}$ & $\begin{array}{l}\text { Not disclosing } \\
\text { slippage } \\
\text { issues. }\end{array}$ \\
\hline Buyer & $\begin{array}{l}\text { Signed } \\
\text { contract }\end{array}$ & $\begin{array}{l}\text { Maximum } \\
\text { price } \\
\text { willing to } \\
\text { offer }\end{array}$ & $\begin{array}{l}\text { Not discussing } \\
\text { development } \\
\text { opportunities }\end{array}$ \\
\hline Council & $\begin{array}{l}\text { Files, L.I.M, } \\
\text { consents }\end{array}$ & $\begin{array}{l}\text { Explanation } \\
\text { of the files }\end{array}$ & $\begin{array}{l}\text { Files not } \\
\text { available, } \\
\text { Council errors }\end{array}$ \\
\hline Lawyer & $\begin{array}{l}\text { Check all } \\
\text { relevant } \\
\text { documents }\end{array}$ & $\begin{array}{l}\text { Personal } \\
\text { opinions }\end{array}$ & $\begin{array}{l}\text { Fee } \\
\text { transparency }\end{array}$ \\
\hline Agent & $\begin{array}{l}\text { Refer to } \\
\text { council and } \\
\text { information } \\
\text { received from } \\
\text { the seller }\end{array}$ & $\begin{array}{l}\text { Paints a } \\
\text { tacit picture } \\
\text { of a } \\
\text { property }\end{array}$ & $\begin{array}{l}\text { Withholding } \\
\text { information if } \\
\text { that could } \\
\text { negate the sale }\end{array}$ \\
\hline Banker & $\begin{array}{l}\text { Calculate the } \\
\text { monthly } \\
\text { payment }\end{array}$ & $\begin{array}{l}\text { Sell their } \\
\text { service }\end{array}$ & $\begin{array}{l}\text { Not compare } \\
\text { every } \\
\text { mortgage }\end{array}$ \\
\hline Specialist & $\begin{array}{ll}\text { Develop } & \text { a } \\
\text { report }\end{array}$ & $\begin{array}{l}\text { Sell their } \\
\text { service }\end{array}$ & $\begin{array}{l}\text { Not liable for } \\
\text { their report. }\end{array}$ \\
\hline
\end{tabular}

Table 5: Examples of TEX per Stakeholder

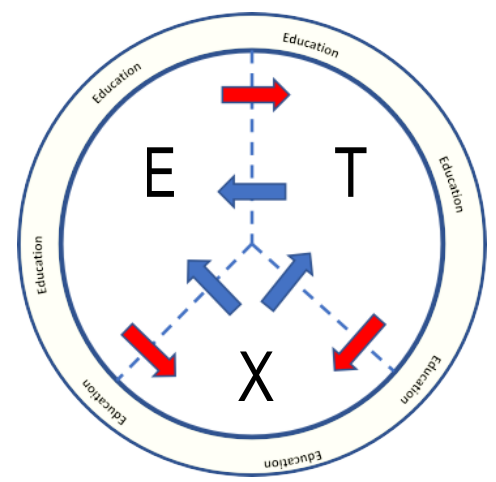

Figure 4: TEX model flows

Given the characteristics of HVLVT, blockchain could be a suitable solution to address several of our concerns. For example, verifiable information could be stored onto some permissioned blockchain. This could address the issue of information asymmetry in many ways. First, all information would be time- stamped, situating the data in a historical context. Second, information would be verifiable since it will only be entered through trusted nodes. Third, it can give legal standing to the buyer if the information used to make a purchase decision was incorrect. Fourth, the same information previously collected does not have to be repeatedly sourced again, thus saving time and money.

\section{Discussion and Conclusion}

A poignant remark made by one participant is that councils in NZ have a bad reputation in archiving all the information on houses in their area. To evade this criticism councils often apologise by stating they have had a "fire in their records." In the meantime, nearly every council office at some point has experienced this "fire". This is a classic example of explicit information being lost. Throughout the interviews, there have been numerous examples of information flowing between the various TEX dimensions. Figure 5 summarises the remarks gathered from the case study on the information flow between $\mathrm{T}, \mathrm{E}$ and $\mathrm{X}$ dimensions.

The problem that arises is the motivational aspect of the stakeholders to participate in the information exchange on the blockchain. We need to understand their financial loss or gain in sharing information and list motivations per stakeholder to share verifiable information and how we can verify this information. Initially, from the seven stakeholders, only two benefit directly from the introduction of blockchain. The council increases its detailed information per household. The buyer lowers his cost in the due diligence process and benefits from the increased amount of verifiable data. We believe the government would need to be the catalyst to drive change in this space and motivate other stakeholders to change their behaviour. As mentioned, reducing both risk and initial cost in a transaction is the driving force. Counterbalancing the asymmetric information and increasing the knowledge and trust on the asset to be transacted, would be the largest contributors to risk reduction.

As an incentive for the seller to participate in the transparency of the asset, the reduction of risk could have a positive impact on the sales price. There is a correlation between risk and the price a buyer is willing to offer. A buyer will counteract the risk by building in a margin to offset the perceived risk [29]. There is also a motivation for the specialist involved if we can convince seller before listing their property to acquire and register the reports on the blockchain to present an in-depth picture of their asset, thus reducing the buyer's risk. If we can motivate the buyer and seller to utilise blockchain for information sharing and use government as an initiator, we can counterbalance information asymmetry in HVLFT.

As illustrated in Figure 5 we view the knowledge and information flows between the various stakeholders as potential contributors to asymmetric information. If we can focus our procedural and technological responses on these information flows, we can reduce 
information asymmetry in a HVLFT. From the case study we have identified and discussed two main contributors towards asymmetric information in a HVLFT (X, noise, and education). In a HVLFT there are also a number of subtle contributors that influence asymmetric information in a positive or negative way (i.e. honesty, trust, financial gain,). These subtle contributors could be incorporated in a system dynamics model, namely a stock and flow diagram (Figure 6).
This model enables us to modify the input and present the results in an interface to visualize the degree of risk associated with a HVLFT. Quantifying the amount of risk that is acceptable would require further research. This would increase our understanding of what contributes to asymmetric information and in how we could be observant of other factors that contribute towards asymmetric information.

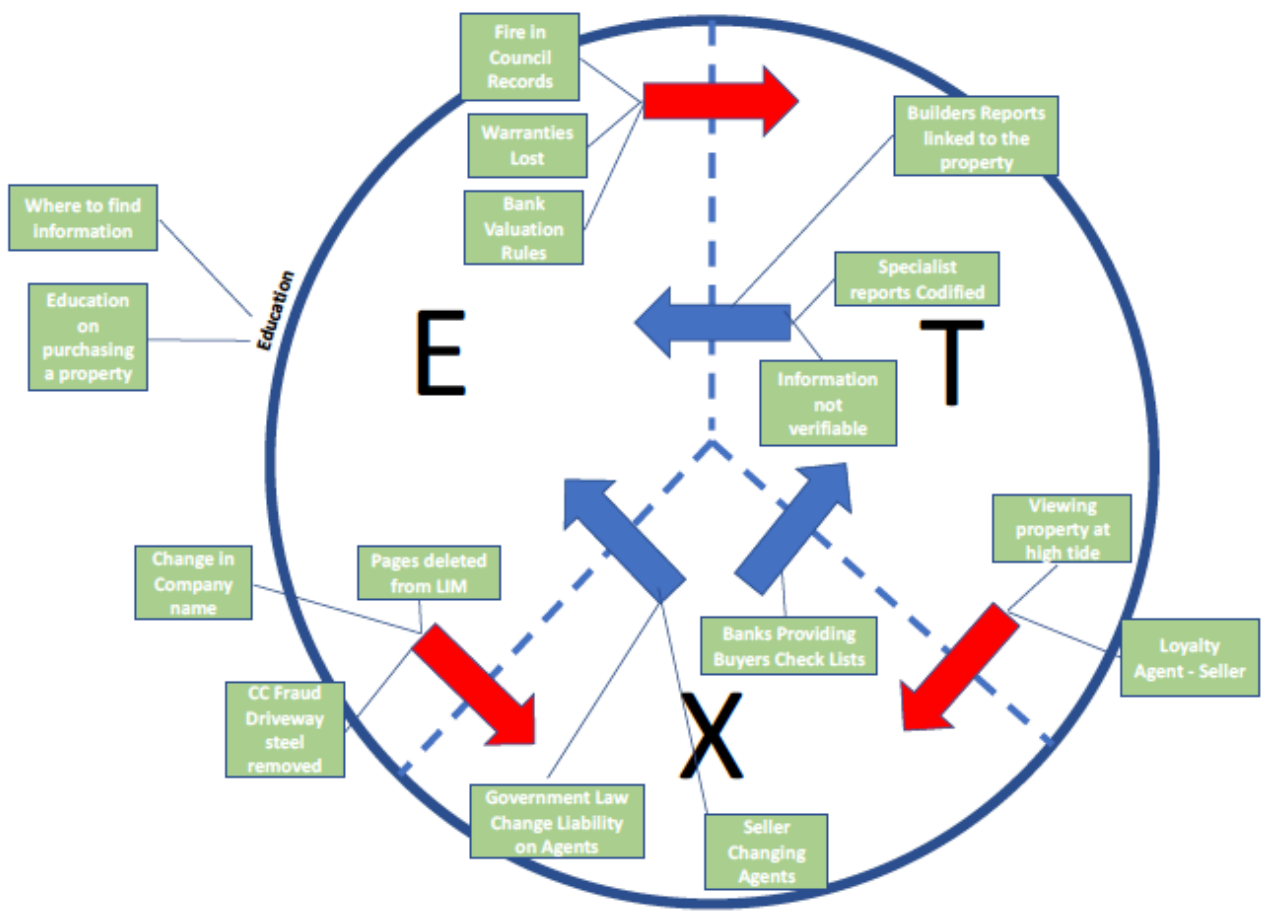

Figure 5: Information flow between dimensions based on participants remarks
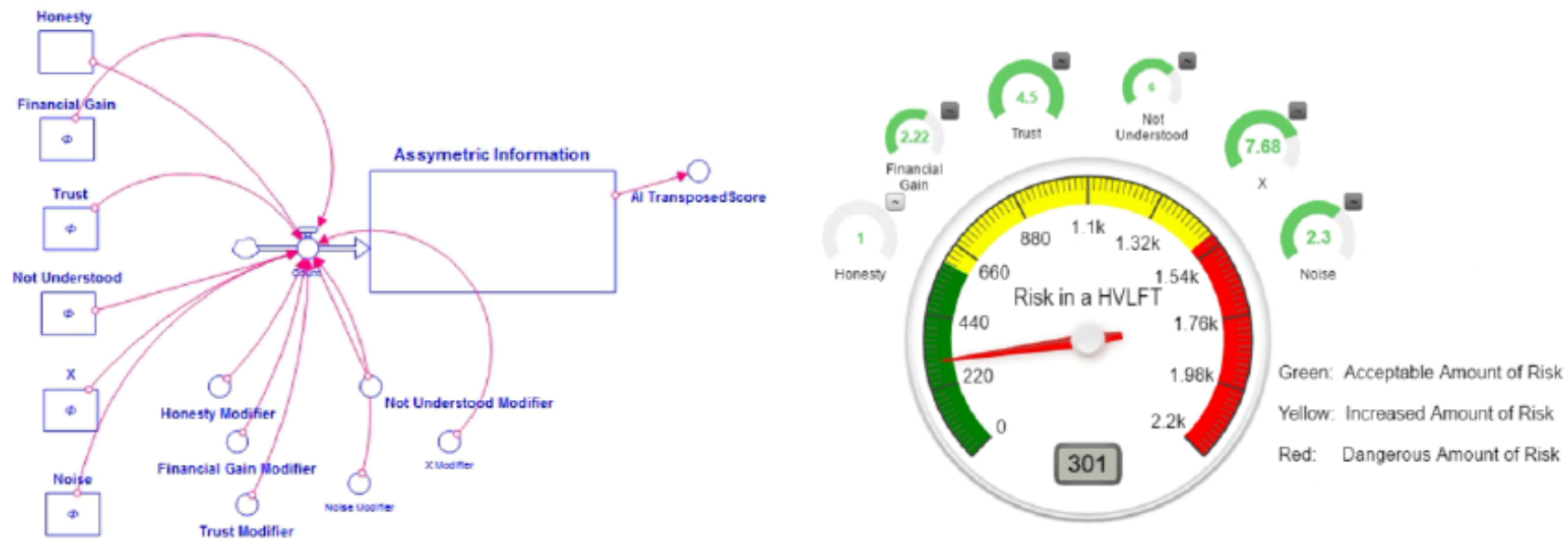

Figure 6: Stock and Flow Diagram Modifying and Visualizing Risk in Asymmetric Information 


\section{References}

[1] Akerlof, G.A., "The market for 'lemons': Quality uncertainty and the market mechanism", The Quarterly Journal of Economics 84(3), 1970, pp. 488-500.

[2] Alavi, M., and D.E. Leidner, Review: Knowledge Management and Knowledge Management Systems: Conceptual Foundations and Research Issues, 2001.

[3] Alter, S., "Goals and tactics on the dark side of knowledge management", Proceedings of the Annual Hawaii International Conference on System Sciences, IEEE (2006), 144a-144a.

[4] Argyris, C., and D.A. Schon, Theory in practice: Increasing professional effectiveness., Jossey-Bass, Oxford, England, 1974.

[5] Brooking, A., Corporate Memory: Strategies For Knowledge Management, London International Thomson Business 1999, London, 1999.

[6] Carlsen, B., and C. Glenton, "What about N? A methodological study of sample-size", BMC Medical Research Methodology, 2011.

[7] Chang, H.H., and S.S. Chuang, "Social capital and individual motivations on knowledge sharing: Participant involvement as a moderator", Information and Management 48(1), 2011, pp.9-18.

[8] Chrzanowska, J., Interviewing groups and individuals in qualitative market research, SAGE Publications Ltd, Thousand Oaks, Calif., 2010.

[9] Cibangu, S.K., "A memo of qualitative research for information science: Toward theory construction", Journal of Documentation(69), 2013, pp. 194-213.

[10] Collins, H., Tacit and Explicit Knowledge, University of Chicago Press, 2013.

[11] Dalkir, K., Knowledge Management in Theory and Practice, Cambridge, MA : MIT Press, 2017.

[12] Davenport, T.H., and Laurence. Prusak, Working knowledge : how organizations manage what they know, Harvard Business School Press, 1998.

[13] Davies, M., Knowledge (Explicit, Implicit and Tacit): Philosophical Aspects, Elsevier, Amsterdam :, 2015.

[14] Dreyfus, S.E., "The five-stage model of adult skill acquisition", Bulletin of Science, Technology and Society 24(3), 2004, pp. 177-181.

[15] Duguid, P., “"The art of knowing': Social and tacit dimensions of knowledge and the limits of the community of practice", Information Society 21(2), 2005, pp. 109118.

[16] Eisenhardt, K.M., "Building Theories from Case Study Research", Academy of Management Review 14(4), 1989, pp. 532-550.

[17] Engwall, L., "Research Note: Linguistic Analysis of an Open-ended Questionnaire in an Organizational Study", Organization Studies 4, 1983, pp. 261-270.

[18] Epstein, L.G., and M. Peters, "A Revelation Principle for Competing Mechanisms", Journal of Economic Theory 88(1), 1999, pp. 119-160.

[19] Fahey, L., and L. Prusak, The Eleven Sins of Knowledge Management, 1998.

[20] Ferdinand, J., and D. Simm, "A Different Look at Sticky and Leaky Knowledge: Economic and Industrial Espionage", the International Conference on Organizational Learning, Knowledge and Capabilities, (2006), 1-25.
[21] Goffman, E., The presentation of self in everyday life, Penguin 1971, Harmondsworth, 1971.

[22] Gottlieb, D., "Asymmetric information in late 19th century cooperative insurance societies", Explorations in Economic History 44(2), 2007, pp. 270-292.

[23] Hedesstrom, T., and E.A. Whitley, "What is meant by tacit knowledge? Towards a better understanding of the shape of actions", European Conference on Information Systems, (2000), 46-51.

[24] Hendel, I., and A. Lizzeri, American Economic Association Adverse Selection in Durable Goods Markets, 1999.

[25] Hoksbergen, M., J. Chan, G. Peko, and D. Sundaram, "Counterbalancing the Asymmetric Information Paradigm on High-Value Low-Frequency Transactions", Proceedings of the 53rd Hawaii International Conference on System Sciences, (2020), 4685-4692.

[26] Hoksbergen, M., J. Chan, G. Peko, and D. Sundaram, "Illuminating the VorteX between the Tacit and the Explicit: Bridging the Knowledge Gap in High- Value Low-Frequency Transactions", AMCIS 2020 Proceedings, (2020).

[27] Holmstrom, B., "Moral Hazard and Observability", The Bell Journal of Economics 10(1), 1979, pp. 74.

[28] Jones, J.W., A.M. McCosh, M.S.S. Morton, and P.G. Keen, "Management Decision Support Systems.", Administrative Science Quarterly 25(2), 1980.

[29] Kim, D.J., D.L. Ferrin, and H.R. Rao, "A trust-based consumer decision-making model in electronic commerce: The role of trust, perceived risk, and their antecedents", Decision Support Systems 44(2), 2008, pp. 544-564.

[30] Laffont, J.-J., and D. Martimort, "Collusion Under Asymmetric Information”, Econometrica 65(4), 1997, pp. 875.

[31] Malterud, K., V.D. Siersma, and A.D. Guassora, "Sample Size in Qualitative Interview Studies: Guided by Information Power", Qualitative Health Research 26(13), 2016, pp. 1753-1760.

[32] Maqsood, T., A. Finegan, and H. Armstrong, "Biases and Heuristics in Judgment and Decision Making: The Dark Side of Tacit Knowledge", Issues in Informing Science and Information Technology 1, 2004, pp. 0295-0301.

[33] Mason, M., "Sample size and saturation in $\mathrm{PhD}$ studies using qualitative interviews", Forum Qualitative Sozialforschung, 2010.

[34] Miles, M.B., and A.M. Huberman, Qualitative data analysis: expanded sourcebook, Sage Publications, Thousand Oaks, California, USA, 1994.

[35] Mishkin, F.S., "Asymmetric information and financial crises: A historical perspective", In Financial Markets and Financial Crises. Cambridge, MA, 1991, 69-108.

[36] Myers, M.D., Qualitative research in business management, Sage publications, London, 2013.

[37] Myerson, R.B., "Incentive Compatibility and the Bargaining Problem", Econometrica 47(1), 1979.

[38] Myerson, R.B., "Optimal Auction Design”, Mathematics of Operations Research 6(1), 1981.

[39] Myerson, R.B., "Mechanism Design by an Informed Principal", Econometrica 51(6), 1983, pp. 1767.

[40] Neelawala, S., "Asymmetric Information between Buyers and Sellers in the residential property market: A Hedonic Property Valuation Approach", 2014.

[41] Nonaka, I., and Hirotaka. Takeuchi, The knowledgecreating company: how Japanese companies create the 
dynamics of innovation, Oxford University Press, New York, 1995.

[42] Polanyi, M., The tacit dimension, Anchor Books, New York, 1966.

[43] Pope, J.C., "Buyer information and the hedonic: The impact of a seller disclosure on the implicit price for airport noise", Journal of Urban Economics 63(2), 2008, pp. 498-516.

[44] Racz, N., E. Weippl, and A. Seufert, "A frame of reference for research of integrated Governance, Risk and Compliance (GRC)", Lecture Notes in Computer Science, Springer, Heidelberg (2010), 106-117.

[45] Riley, J.G., and W.F. Samuelson, "Optimal auctions", The American Economic Review 71(3), 1981, pp. 381392.

[46] Rosen, S., Hedonic Prices and Implicit Markets: Product Differentiation in Pure Competition, 1974.

[47] Rothschild, M., and J. Stiglitz, "Equilibrium in Competitive Insurance Markets: An Essay on the
Economics of Imperfect Information", The Quarterly Journal of Economics 90(4), 1976, pp. 629.

[48] Seidl, D., "The dark side of knowledge", Complexity and Organization 9(3), 2007, pp. 16-29.

[49] Seidmann, A., and A. Sundararajan, "The effects of task and information asymmetry on business process redesign", International Journal of Production Economics 50(2-3), 1997, pp. 117-128.

[50] Spence, M., "Job Market Signaling", The Quarterly Journal of Economics 87(3), 1973, pp. 355

[51] Szulanski, G., "The Process of Knowledge Transfer: A Diachronic Analysis of Stickiness", Organizational Behavior and Human Decision Processes 82(1), 2000, pp. 9-27.

[52] Yin, R.K., "Discovering the Future of the Case Study Method in Evaluation Research", American Journal of Evaluation 15(3), 1994, pp. 283-290. 